\title{
Exploring the Unique Skills and Challenges Disabled Veterans Bring to Col- lege: A Qualitative Study in Engineering
}

\section{Mr. Michael Scott Sheppard Jr., Arizona State University, Polytechnic campus}

Michael Scott Sheppard Jr. is a graduate research associate pursuing a Master of Science degree in Engineering and a Ph.D. in Engineering Education Systems and Design at Arizona State University. He received a B.S. degree in Biomedical Science from Lynchburg College in 2002, after which he served in the military for 6 years as a Special Amphibious Reconnaissance Corpsman. Following military service, Michael obtained a B.S. degree in Engineering from Arizona State University, graduating in 2013. His research interests include veterans in engineering, veterans with service-connected disability, post-traumatic stress disorder (PTSD), and human sex trafficking. 
Background Military careers and student life have stark differences. No matter each veteran's military job or experiences, a transition of this nature will be fraught with unexpected challenges. Disabled student veterans may face challenges that uniquely differentiate them from other students and other veterans. Alternatively, they may find themselves better suited than others to navigate an undergraduate engineering program.

Purpose This exploratory research study aims to develop a deeper understanding of the experiences of engineering student veterans with service-connected disabilities as they transition into higher education.

Design/Method To investigate these transitions, we utilized semi-structured narrative interviews with three sophomore engineering students with levels of service-connected disability exceeding 30 percent, purposively selected for maximum variability across particular demographic characteristics. In this thematic analysis, we explored the rich narratives of the students' transitions from military members to undergraduate engineering students by coding the data and organizing the themes as they mapped to the Schlossberg Transition Theory.

Findings Preliminary analysis of the data confirms an agreement among disabled veterans that service-connected disabilities and the loss of social support networks have proven to create challenges in and out of the classroom. However, their military time and training have positively affected their transition and ensuing successes as engineering students. The identification of these unique skills and challenges affords us a better chance to understand these aspects of transition and facilitate change to utilize successful strategies and better support future disabled student veterans and disabled students who are not veterans.

Keywords student veterans; disabled veterans; veterans in engineering 